\title{
Dual-functional use of thread delivery hood for traction-assisted rectal endoscopic submucosal dissection and defect closure
}

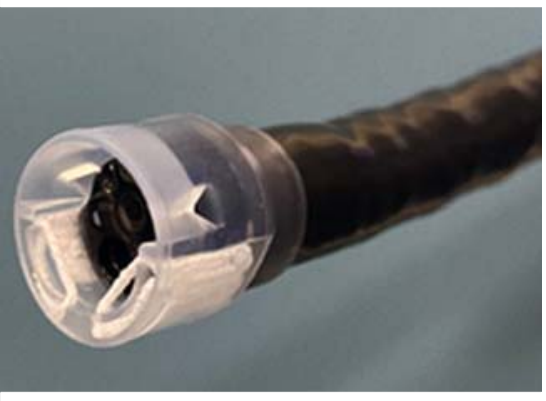

> Fig. 1 Dual Traction Hood, which has dual threads with multi-rings inside the cap.

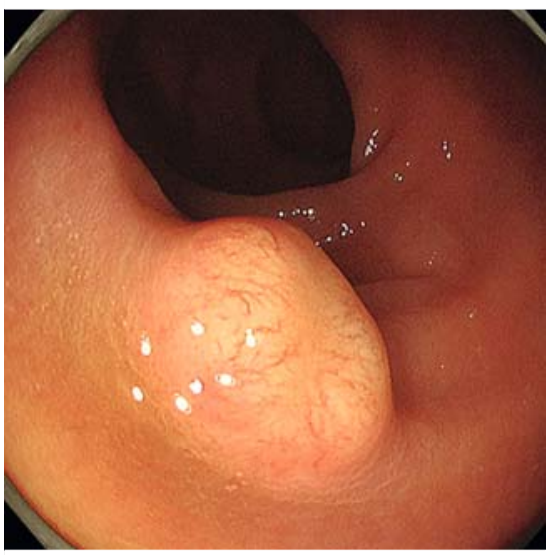

- Fig. 2 Rectal endoscopic submucosal dissection was performed on a neuroendocrine tumor $8 \mathrm{~mm}$ in diameter.

Endoscopic closure of an artificial defect after colorectal endoscopic submucosal dissection (ESD) is useful in preventing adverse events [1], with several closure methods having been developed [2,3]. While the use of traction facilitates ESD [4], no devices currently exist that can facilitate both traction and closure. An elastic thread delivery hood (Dual Traction Hood; Adachi Co., Ltd., Osaka, Japan and Nomura Medical Device Co., Ltd., Nagano, Japan) that has dual threads with multi-rings inside the cap has been developed for traction use (> Fig. 1) [5]. We describe a case in which this device

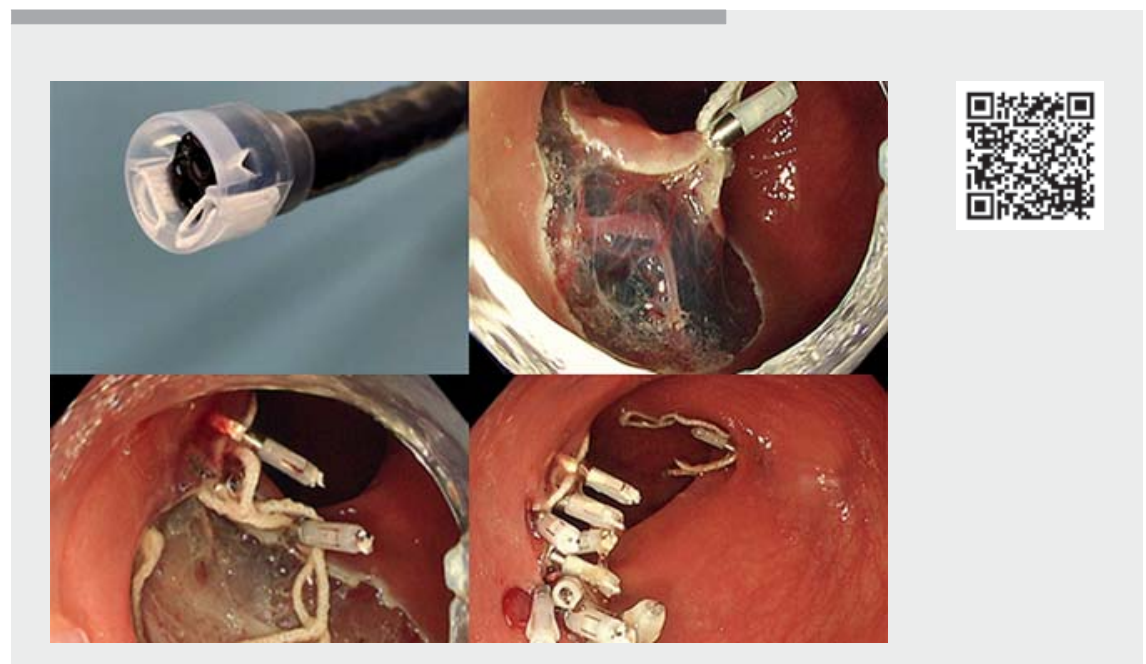

Video 1 A Dual Traction Hood was used successfully for traction as well as closure in a rectal endoscopic submucosal dissection.

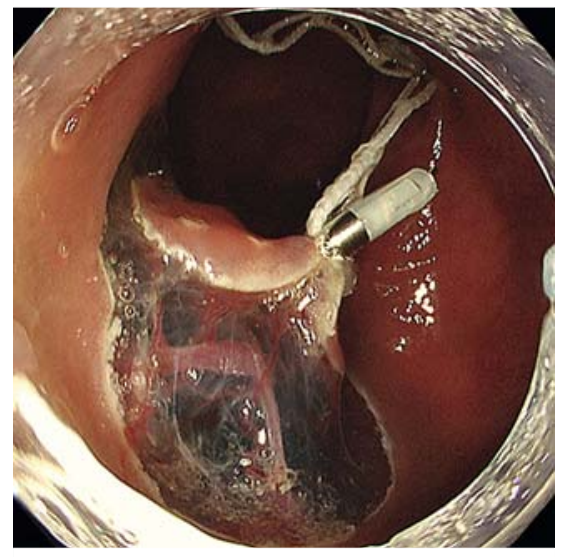

- Fig. 3 Traction facilitated rectal endoscopic submucosal dissection after the thread was fixed to the edge of the pocket and opposite the normal mucosa using hemoclips.

was used successfully for traction as well as closure in a rectal ESD ( $\triangleright$ Video 1 ).

A 65-year-old man presented with a rectal neuroendocrine tumor ( $\triangleright$ Fig. 2). Rectal ESD was performed using a Dual Traction Hood as follows. The first thread was used for the traction. After a submucosal pocket was created followed by a whole

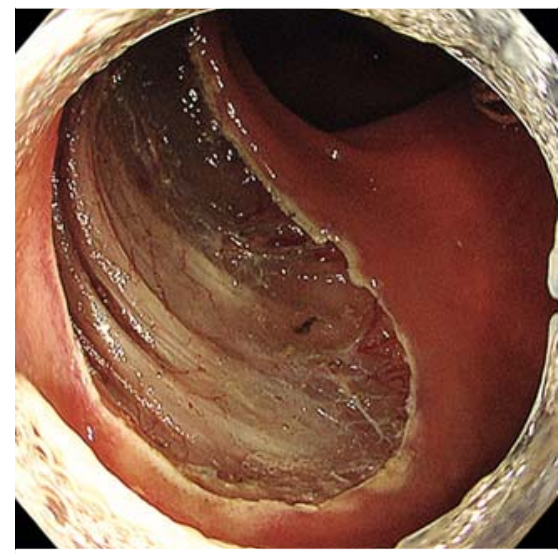

Fig. 4 An artificial defect $30 \mathrm{~mm}$ in diameter after endoscopic submucosal dissection.

circumferential incision, the thread was released from the hood using a hemoclip (HX-610-090; Olympus, Tokyo, Japan). Using hemoclips, the thread was then fixed to the edge of the pocket and the opposite normal mucosa ( Fig.3). Traction-assisted ESD was completed successfully, leaving an artificial defect $30 \mathrm{~mm}$ wide (\ Fig.4). 


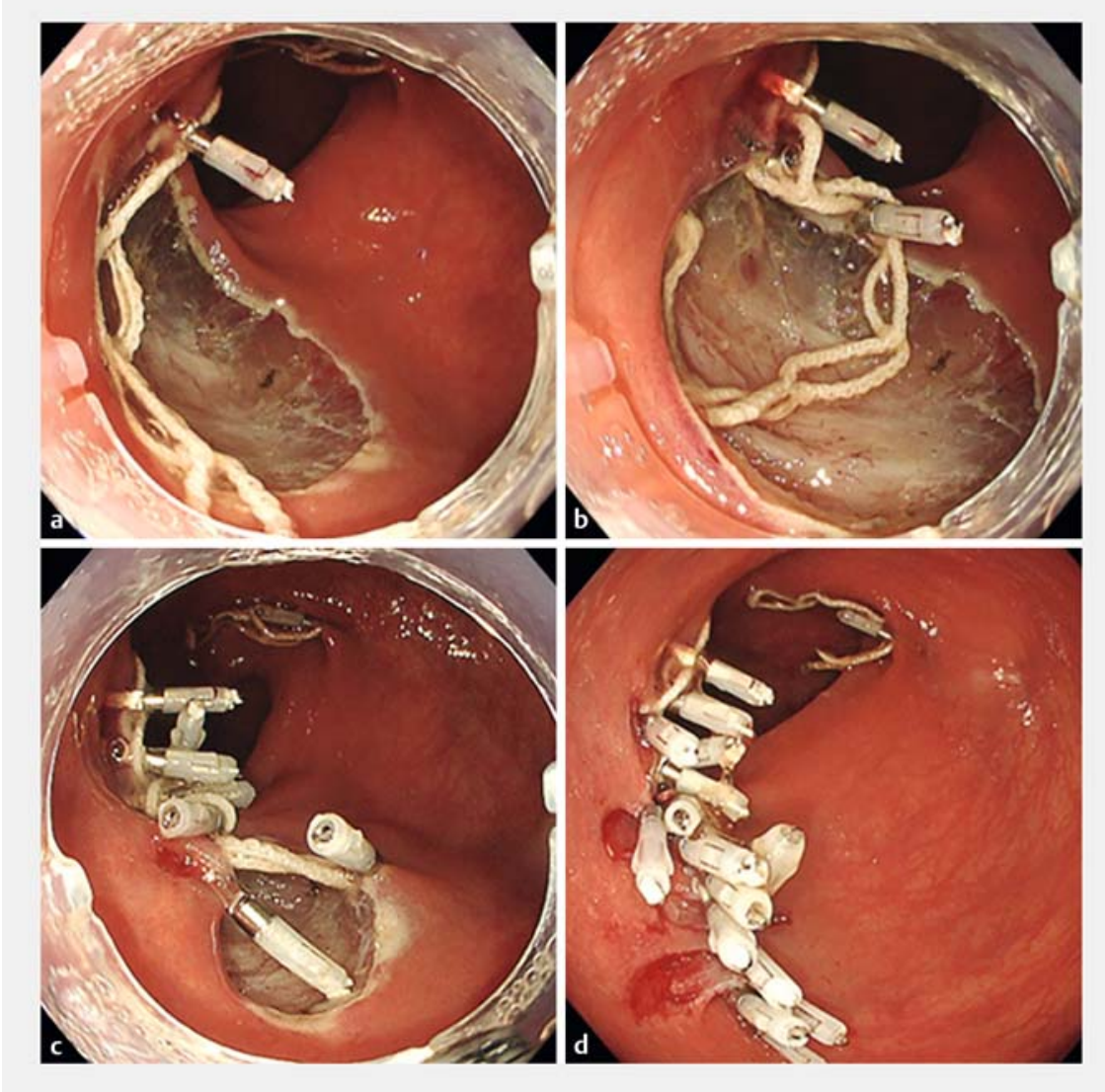

- Fig. 5 a-c One ring of the thread was anchored to the defect edge using a hemoclip, and another ring was anchored to the opposite edge. The defect was approximated by these hemoclips. The thread was then anchored to both edges in a zig-zag pattern. $\mathbf{d}$ Complete closure was achieved using additional hemoclips.

The second thread was used to close the defect post-ESD. One ring of the thread was anchored to the defect edge using a hemoclip, and another ring was anchored to the opposite edge. The procedure was repeated in a zig-zag pattern while the thread was attached to both edges. Consequently, the defect was approximated by these hemoclips. Complete closure was achieved with additional hemoclips ( Fig.5). The ESD and closure took 20 and 15 minutes, respectively.

The Dual Traction Hood enabled clinicians to achieve both traction-assisted ESD and endoscopic defect closure. This method may become an effective option in facilitating ESD and preventing delayed complications.

Endoscopy_UCTN_Code_TTT_1AQ

\section{Competing interests}

The authors declare that they have no conflict of interest.

The authors

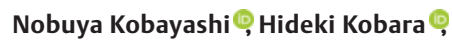
Kazuhiro Kozuka, Naoya Tada, Takanori

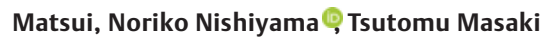
Department of Gastroenterology and Neurology, Faculty of Medicine, Kagawa University, Japan

\section{Corresponding author}

Nobuya Kobayashi, MD, PhD

Department of Gastroenterology and

Neurology, Faculty of Medicine, Kagawa

University, 1750-1 Ikenobe, Miki, Kita,

Kagawa 761-0793, Japan

Fax: +81-87-891-2158

nobuyak@med.kagawa-u.ac.jp

[1] Ogiyama H, Tsutsui S, Murayama Y et al. Prophylactic clip closure may reduce the risk of delayed bleeding after colorectal endoscopic submucosal dissection. Endosc Int Open 2018; 6: E582-E588

[2] Abe S, Saito Y, Tanaka Y et al. A novel endoscopic hand-suturing technique for defect closure after colorectal endoscopic submucosal dissection: a pilot study. Endoscopy 2020; 52: 780-785

[3] Kato M, Takeuchi Y, Yamasaki Y et al. Technical feasibility of line-assisted complete closure technique for large mucosal defects after colorectal endoscopic submucosal dissection. Endosc Int Open 2017; 5: E11-E16

[4] Saito Y, Parra-Blanco A. Traction is most important for the widespread use of endoscopic submucosal dissection, especially in procedures presenting particular difficulty. Endoscopy 2020; 52: 328-329

[5] Fujita K, Takeshita M, Moriyama E et al. Novel technique for endoscopic submucosal dissection using an elastic thread delivery hood. Endoscopy 2020; 52: E178-E180

Bibliography

Endoscopy 2022; 54: E108-E109

DOI 10.1055/a-1381-6363

ISSN 0013-726X

published online 30.3.2021

(c) 2021. Thieme. All rights reserved.

Georg Thieme Verlag KG, Rüdigerstraße 14, 70469 Stuttgart, Germany

\section{ENDOSCOPY E-VIDEOS}

https://eref.thieme.de/e-videos

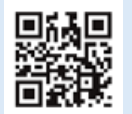

Endoscopy E-Videos is an open access online section, reporting on interesting cases and new techniques in gastroenterological endoscopy. All papers include a high quality video and all contributions are freely accessible online. Processing charges apply (currently EUR 375), discounts and wavers acc. to HINARI are available.

This section has its own submission website at https://mc.manuscriptcentral.com/e-videos 